\title{
Trapeziohamate Distance in Carpal Tunnel View as a Risk Factor for Carpal Tunnel Syndrome
}

\author{
Davod Jafari, ${ }^{1}$ Farid Najd Mazhar,' Samad Joudi," Hasan Keyhan Shokooh, ${ }^{1}$ Hooman \\ Shariatzadeh, and Payam Hassani Shariat Panahy ${ }^{3}$ \\ ${ }^{1}$ Bone and Joint Reconstruction Research Center, Shafa Orthopedic Hospital, Iran University of Medical Sciences, Tehran, IR Iran \\ ${ }^{2}$ Department of Orthopedic Surgery, Beasat Hospital, Hamedan University of Medical Sciences, Hamedan, IR Iran \\ ${ }^{3}$ Universiti Putra Malaysia, Serdang, Selangor, 43400, Malaysia \\ *Corresponding author: Samad Joudi, Bone and Joint Reconstruction Research Center, Shafa Orthopedic Hospital, Iran University of Medical Sciences, Tehran, IR Iran. Tel: \\ +98-9127314450, Fax: +98-2133542020, E-mail: samadjoudi@yahoo.com
}

Received 2015 August 25; Accepted 2015 September 22.

\begin{abstract}
Background: Carpal tunnel syndrome(CTS) is the most frequent entrapment syndrome of the upper limp, which leads to compression of the median nerve at the level of the wrist. Any early diagnosis based on the radiological and clinical findings is essential to find a risk factor preventing permanent nerve damage and functional sequelae.

Objectives: The main aim of this study was to evaluate and determine trapeziohamate distance as a risk factor for incident CTS.

Patients and Methods: The subjects in this case-control study were patients divided into an experimental group $(\mathrm{n}=38)$ and control group $(n=23)$. Prospective study was conducted on 33 female and 5 male patients with CTS and 21 females and 2 males in control group. Subjects were selected from patients and their relatives who referred to our hand surgery department. In total, 61 subjects were examined. Gender and age as the personal factors, dominant hand, diabetes mellitus (DM), occupation and trapeziohamate distances were evaluated in all patients and control group. Mean values of trapeziohamate distance as a risk factor for experimental and control groups were measured. Levene's test and Student's t test were used to analyse the collected data using Statistical Package for Social Science.

Results: The risk of CTS was higher in women and housekeeper. There was a significant difference between the two groups for trapeziohamate distance. The mean of trapeziohamate distance in control group (23.39) was significantly higher than the mean of experimental group (21.02).

Conclusions: Our study confirmed that the incidence of CTS is higher in women and housekeeper and trapeziohamate distance is a dependent risk factor for the carpal tunnel syndrome.

Keywords: Carpal Tunnel Syndrome, Trapezium, Trapeziohamate, Carpal Tunnel View
\end{abstract}

\section{Background}

Carpal tunnel syndrome (CTS) is a common median nerve compression neuropathy at the level of wrist (1). It causes numbness and pain in the volar surface of the thumb through the radial half of the ring finger (2). CTS represent a major occupational health problem with high social and economic implications (3). Surgical release of median nerve in the majority of cases is required if conservative treatment is not successful (4). An early diagnosis based on clinical findings is essential to prevent nerve damage and functional sequelae (5). Then, examination and clinical findings are valuable tools for identifying the risk factors of carpal tunnel syndrome.

Several study have attempted to identify the risk factors of carpal tunnel syndrome (1, 3, 6-9). They identified different personal and medical risk factors of CTS such as age, gender, overweight, arthritis, diabetes mellitus, rheumatoid and thyroid disorders (1, 3, 6-9). They empha- sized that middle age (40 - 60 years) and female gender are the most significant risk factors of CTS that are not modifiable (3). Despite the growing number of studies on risk factors for CTS, lack of consensus regarding the distance between trapezium and hamate in the carpal tunnel view is remained.

\section{Objectives}

Our aim in this study was to assess the association of distance between trapezium and hamate factor on the incidence of CTS, with a special focus on age, gender, dominant hand, diabetes mellitus and occupation.

\section{Patients and Methods}

The subjects were chosen among 61 patients ( 7 males, 54 females) with a mean age of 50 years (ranged $46-55$

Copyright (C) 2015, Iran University of Medical Sciences. This is an open-access article distributed under the terms of the Creative Commons Attribution-NonCommercial 4.0 International License (http://creativecommons.org/licenses/by-nc/4.0/) which permits copy and redistribute the material just in noncommercial usages, provided the original work is properly cited. 
years) and more females ( $\mathrm{n}=33,86.8 \%)$ than males $(\mathrm{n}=5$, 13.2\%), who visited outpatient clinics from October 2012 to April 2013. The case-control study was carried out on all patients who underwent carpal tunnel release due to classic clinical and electro diagnostic findings of CTS at the Department of Hand surgery in Shafa Hospital in Iran. We included only patients with idiopathic form of CTS. Any patients with ipsilateral upper extremity trauma and fracture history, pregnant cases and all patients with secondary CTS were excluded from the study together with those who did not agree to take part in the study for any reasons. Each subject provided informed consent for participation in this study at baseline, and the study received approval from the Institutional Review Board.

We performed carpal tunnel view of the involved wrist in addition to the routine X-rays. For control group, we used the carpal tunnel view X-ray from volunteers who will take part in the study. The carpal tunnel view was obtained as the patients stood with back facing the table and palmar surface of hand is placed in contact with the cassette. The wrist was dorsiflexed approximately 135 degrees, which made the carpals and metacarpals lift away from the cassette (10). The beam is angled to profile the carpal tunnel by directing it along the volar aspect to a point $2.5 \mathrm{~cm}$ distal (11). To determine the trapeziohamate distance we calculated the narrowest distance between the ridge of the trapezium and hook of the hamate (Figure 1).

Demographic and clinical data were entered a database constructed for this study and data analyzed using Statistical Package for Social Science (SPSS version 20, IBM Corporation, Armonk, NY). For comparisons between the two groups, we used student's t test for different variances. $\mathrm{P}$ value of 0.05 or less was considered statistically significant. Results were shown as a mean \pm SD. Normality was checked prior to each analysis. Kolmogorov-Smirnov test (KS test) was used to test the normal distribution of variables. Levene's test was used to determine homogeneity of variance, with $\mathrm{P}<0.05$. Since, its results indicated that variances are homogeneous, Student t test (2-tailed) with confidence level of $95 \%$ was used to assess differences between experimental and control groups.

\section{Results}

The study lasted 7 months and in this period we performed examination of patient's hand in 38 patients in experimental group and 23 patients in control group. Dominant hand of the experimental group was right hand ( $\mathrm{n}=36,94.7 \%)$, and overall involved hand of this group was also right hand ( $\mathrm{n}=24,63.2 \%$ ). In addition, $65.8 \%$ of patients in the experimental group did not have any underlying diseases. Regarding their occupation, most of them were housekeepers $(n=24,63.2 \%)$ followed by employee ( $n=9,23.7 \%)$ and worker $(n=5,13.2 \%)$.

In the control group, examination of hand in 23 patients was performed. The mean age of patients was 42 years (ranged 36 - 45 years), with more females $(n=21$,
91.3\%) than males ( $n=2,8.7 \%)$. Dominant hand of the control group was the right hand $(n=20,87 \%)$. In addition, $78.3 \%$ of patients of control group had not any underlying diseases. Furthermore, regarding occupation, 69.6\% of patients were housekeepers $(n=16)$ followed by employee $(n=2,8.7 \%)$ and worker $(n=2,8.7 \%)$. The general characteristics of the patients are shown in Table 1.

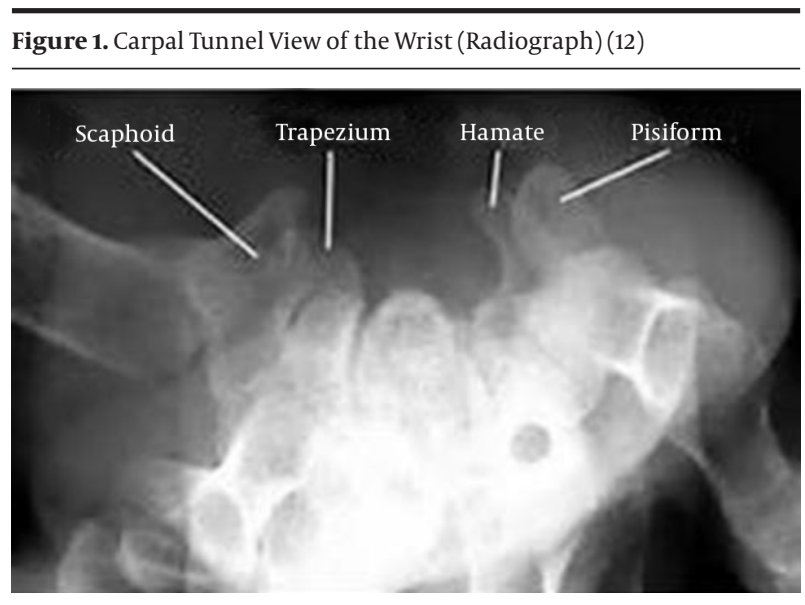

Prior to the study we evaluated inter and intra observer reliability of this measurement using the intraclass correlation coefficient (ICC). The calculated values of ICC were 0.672 and 0.605 respectively, which is considered good.

\begin{tabular}{|c|c|c|}
\hline Characteristics & $\begin{array}{l}\text { Experimental } \\
\text { Group }(n=38)\end{array}$ & $\begin{array}{c}\text { Control Group } \\
(\mathbf{n}=23)\end{array}$ \\
\hline Mean age, y & $46-55$ & $36-45$ \\
\hline \multicolumn{3}{|l|}{ Gender } \\
\hline Female & 87 & 91.3 \\
\hline Male & 13 & 8.7 \\
\hline \multicolumn{3}{|l|}{ Dominant hand } \\
\hline Right hand & 94.7 & 87 \\
\hline Left hand & 5.3 & 13 \\
\hline \multicolumn{3}{|c|}{ Underlying disease $^{b}$} \\
\hline $\begin{array}{l}\text { DM+(Diabetes } \\
\text { Mellitus) }\end{array}$ & 21.2 & 17.4 \\
\hline+ & 13.2 & 4.3 \\
\hline None & 65.8 & 78.3 \\
\hline \multicolumn{3}{|l|}{ Occupation } \\
\hline Housekeeper & 63.2 & 69.9 \\
\hline Employee & 23.7 & 8.7 \\
\hline Worker & 13.2 & 8.7 \\
\hline Others & 0 & 13 \\
\hline
\end{tabular}

${ }^{a}$ Values unit is (\%).

${ }^{b}$ Diagnosis of underlying disease was based on a documented history.

Table 1, summarizes the association between CTS and several factors such as age, gender, dominant hand and occupation assessed in this study. While, diabetes mellitus as 
the underlying diseases was not associated with incidence of CTS, the risk of CTS was higher for women and increased linearly with age. The occupation including housekeepers followed by employee and worker was another risk factor for the incidence of CTS.

In addition, according to the assumption of equal variances, the two groups were significantly different for distance between trapezium and hamate, $\mathrm{t}(59)=-3.94, \mathrm{P}$ $=000$. As depicted in Table 2, the mean of trapeziohamate distance of the experimental group (21.0 $2 \pm 2.4$ ) was significantly lower compared to that of the control group (23.39 \pm 1.9$)$. Comparing mean trapeziohamate distance found that distance between trapezium and hamate is a factor for the incidence of CTS.

Table 2. Comparisons of Mean Trapeziohamate Distance With $95 \% \mathrm{Cl}^{\mathrm{a}}$

\begin{tabular}{lcc}
\hline Characteristics & $\begin{array}{c}\text { Experimental } \\
\text { Group }\end{array}$ & $\begin{array}{c}\text { Control } \\
\text { Group }\end{array}$ \\
\hline $\begin{array}{l}\text { Trapeziohamate } \\
\text { distances }\end{array}$ & $21.02 \pm 2.4$ & $23.39 \pm 1.9$ \\
\hline
\end{tabular}

${ }^{\mathrm{a}}$ Data are presented as mean $\pm \mathrm{SD}$.

\section{Discussion}

Our prospective study provided a unique opportunity to assess the association between trapeziohamate distance with CTS and several factors associated with it. The observed associations provide evidence for not performing routine wrist radiography in evaluation of patients with carpal tunnel syndrome. Regarding personal factors, more CTS was observed in women, in agreement with previous studies $(3,9)$.

The cutoff point of age for CTS as a risk factor varies in different studies $(3,13,14)$. While, some researchers agree that the risk of CTS increases after the age of 30 (14), our result showed that age group between 45 and 55 years is a risk factor for CTS. In addition, our result regarding age group was consistent with those researches indicating that CTS is very rare below the age of 20 (13). Furthermore, our result indicated no association between prevalence of DM and CTS. Although this was similar to some studies $(7,8)$, it was not consistent with other researchers who found that DM is associated with CTS and is considered as its risk factor $(6,9,15)$. Our sample was relatively small, so it is quite possible that this result is related to insufficient sample size. Therefore, further research is needed.

Regarding occupational factor, higher incidence of CTS was observed in housekeepers, which is consistent with some researches indicating that occupation is a risk factor for CTS (3). However, there is a need to assess which type of occupation is more related to CTS.

The main result of study was the association of trapeziohamate distance with CTS. This association was statistically significant in experimental and control groups from the carpal tunnel view. This result is reliable and confirmed, because another researcher emphasized that postero-anterior (PA) and lateral or carpal tunnel views of the wrist are useful when there is wrist pain, limited mobility, deformity or flexor tendon rupture or when medical or history of trauma suggests abnormal tunnel contents (10).

Despite the usefulness of routine wrist radiography in evaluation of patients with carpal tunnel syndrome, only in $0.6 \%$ of patients, radiographic findings had therapeutic significance. Therefore, radiology should no longer be performed routinely in evaluation of patients with CTS, owing to low yield of useful therapeutic information $(10,16)$.

Taken together, it could be hypothesized that trapeziohamate distance in the carpal tunnel view distance is a risk factor for CTS. Careful and complete evaluation of patients with injuries of hand and wrist is required, because miss-diagnoses may cause significant pain and long-term disability.

\section{Acknowledgments}

The authors would like to express their special thanks to all patients who took part in this study and medical personnel of Orthopedic Surgery ward in Shafa Orthopedic Hospital for their cooperation and providing facilities to perform this study.

\section{Footnote}

Authors' Contribution:Study concept and design: Davod Jafari, Farid Najd Mazhar, Hasan Keyhan Shokooh, and Hooman Shariatzadeh; analaysis and interpretation of data: Samad Joudi, and Payam Hassani Shariat Panahy; drafting of the manuscript Farid Najd Mazhar, Samad Joudi, and Payam Hassani Shariat Panahy; critical revision of the manuscript for important intellectual content and study supervision: Farid Najd Mazhar.

\section{References}

1. Miyamoto H, Halpern EJ, Kastlunger M, Gabl M, Arora R, Bellmann-Weiler R, et al. Carpal tunnel syndrome: diagnosis by means of median nerve elasticity-improved diagnostic accuracy of US with sonoelastography. Radiology. 2014;270(2):481-6. doi: 10.1148/radiol.13122901. [PubMed: 24471391]

2. Inui A, Suzuki T, Kokubu T, Sakata R, Mifune Y, Kurosaka M. Carpal Tunnel Syndrome Caused by Tumoral Calcinosis. Case Rep Orthop. 2015;2015:170873. doi: 10.1155/2015/170873. [PubMed: 26266068]

3. Petit A, Ha C, Bodin J, Rigouin P, Descatha A, Brunet R, et al. Risk factors for carpal tunnel syndrome related to the work organization: a prospective surveillance study in a large working population. Appl Ergon. 2015;47:1-10. doi: 10.1016/j.apergo.2014.08.007. [PubMed: 25479968]

4. Campagna R, Pessis E, Feydy A, Guerini H, Le Viet D, Corlobe P, et al. MRI assessment of recurrent carpal tunnel syndrome after open surgical release of the median nerve. AJR Am J Roentgenol. 2009;193(3):644-50. doi:10.2214/AJR.08.1433. [PubMed:19696276]

5. Klauser AS, Halpern EJ, De Zordo T, Feuchtner GM, Arora R, Gruber J, et al. Carpal tunnel syndrome assessment with US: value of additional cross-sectional area measurements of the median nerve in patients versus healthy volunteers. Radiology. 2009;250(1):1717. doi:10.1148/radiol.2501080397. [PubMed:19037017]

6. Oktayoglu P, Nas K, Kilinc F, Tasdemir N, Bozkurt M, Yildiz I. As- 
sessment of the Presence of Carpal Tunnel Syndrome in Patients with Diabetes Mellitus, Hypothyroidism and Acromegaly. J Clin Diagn Res. 2015;9(6):OC14-8. doi: 10.7860/JCDR/2015/13149.6101. [PubMed: 26266148]

7. Hendriks SH, van Dijk PR, Groenier KH, Houpt P, Bilo HJ, Kleefstra N. Type 2 diabetes seems not to be a risk factor for the carpal tunnel syndrome: a case control study. BMC Musculoskelet Disord. 2014;15:346. doi:10.1186/1471-2474-15-346. [PubMed: 25315096]

8. Becker J, Nora DB, Gomes I, Stringari FF, Seitensus R, Panosso JS, et al. An evaluation of gender, obesity, age and diabetes mellitus as risk factors for carpal tunnel syndrome. Clin Neurophysiol. 2002;113(9):1429-34. [PubMed:12169324]

9. Harris-Adamson C, Eisen EA, Dale AM, Evanoff B, Hegmann KT Thiese MS, et al. Personal and workplace psychosocial risk factors for carpal tunnel syndrome: a pooled study cohort. Occup Environ Med. 2013;70(8):529-37. doi: 10.1136/oemed-2013-101365. [PubMed: 23645610]

10. Chammas M. Carpal tunnel syndrome. Chir Main. 2014;33(2):7594. doi:10.1016/j.main.2013.11.010. [PubMed:24646612]

11. Bhat AK, Kumar B, Acharya A. Radiographic imaging of the wrist. Indian J Plast Surg. 2011;44(2):186-96. doi: 10.4103/09700358.85339. [PubMed: 22022028]

12. Watanabe A, Souza F, Vezeridis PS, Blazar P, Yoshioka H. Ulnar-sided wrist pain. II. Clinical imaging and treatment. Skeletal Radiol. 2010;39(9):837-57. doi: 10.1007/s00256-009-0842-3. [PubMed: 20012039]

13. Dumitru D, Zwarts MJ. Focal peripheral neuropathies. Philadelphia: Hanley, Belfus,; 2002.

14. Lam N, Thurston A. Association of obesity, gender, age and occupation with carpal tunnel syndrome. Aust $N$ Z J Surg. 1998;68(3):190-3. [PubMed: 9563447]

15. Karpitskaya Y, Novak CB, Mackinnon SE. Prevalence of smoking, obesity, diabetes mellitus, and thyroid disease in patients with carpal tunnel syndrome. Ann Plast Surg. 2002;48(3):269-73. [PubMed:11862031]

16. Bindra RR, Evanoff BA, Chough LY, Cole RJ, Chow JC, Gelberman $\mathrm{RH}$. The use of routine wrist radiography in the evaluation of patients with carpal tunnel syndrome. J Hand Surg Am. 1997;22(1):115-9. doi: 10.1016/S0363-5023(05)80190-X. [PubMed: 9018623] 